\title{
Identification of CAR/RXR $\alpha$ Heterodimer Binding Sites in the Human Genome by a Modified Yeast One-Hybrid Assay
}

\author{
Kenta Hosoda1, Yuichiro Kanno², Masashi Sato', Jun Inajima², Yoshio Inouye², \\ Kazuyuki Yanai ${ }^{*}$ \\ ${ }^{1}$ Department of Biomolecular Science, Faculty of Science, Toho University, Chiba, Japan \\ ${ }^{2}$ Faculty of Pharmaceutical Sciences, Toho University, Chiba, Japan \\ Email: yanai@biomol.sci.toho-u.ac.jp
}

Received 27 November 2014; accepted 25 March 2015; published 30 March 2015

Copyright (C) 2015 by authors and Scientific Research Publishing Inc.

This work is licensed under the Creative Commons Attribution International License (CC BY). http://creativecommons.org/licenses/by/4.0/

(c) (i) Open Access

\section{Abstract}

The constitutive androstane receptor (CAR) is a transcription factor that belongs to the nuclear receptor superfamily. CAR binds as a heterodimer with the retinoid X receptor $\alpha(\mathrm{RXR} \alpha)$ to CAR response elements (CAREs) and regulates the expression of various drug metabolizing enzymes and transporters. To identify CAR/RXR $\alpha$ binding sites in the human genome, we performed a modified yeast one-hybrid assay that enables rapid and efficient identification of genomic targets for DNA-binding proteins. DNA fragments were recovered from positive yeast colonies by PCR and sequenced. A motif enrichment analysis revealed that the most frequent motif was a direct repeat (DR) of RGKTCA-like core sequence spaced by $4 \mathrm{bp}$. Next, we predicted 149 putative CAR/RXR $\alpha$ binding sites from 414 unique clones, by searching for DRs, everted repeats (ERs) and inverted repeats (IRs) of the RGKTCA-like core motif. Based on gel mobility shift assays, the CAR/RXR $\alpha$ heterodimer could directly interact with the 108 predicted sequences, which included not only classical CAREs but also a wide variety of arrangements. Furthermore, we identified 17 regulatory polymorphisms on the CAR/RXR $\alpha$-binding sites that may influence individual variation in the expression of CAR-regulated genes. These results provide insights into the molecular mechanisms underlying the physiological and pathological actions of CAR/RXR $\alpha$ heterodimers.

\section{Keywords}

Constitutive Androstane Receptor, Retinoid X Receptor, Transcription, SNP, Polymorphism, Nuclear Receptor

\footnotetext{
${ }^{*}$ Corresponding author.

How to cite this paper: Hosoda, K., Kanno, Y., Sato, M., Inajima, J., Inouye, Y. and Yanai, K. (2015) Identification of CAR/ RXR $\alpha$ Heterodimer Binding Sites in the Human Genome by a Modified Yeast One-Hybrid Assay. Advances in Biological Chemistry, 5, 83-97. http://dx.doi.org/10.4236/abc.2015.52008
} 


\section{Introduction}

Constitutive androstane receptor (CAR), a DNA-binding and ligand-regulated transcription factor that belongs to the superfamily of nuclear receptors [1], is mainly expressed in the liver and acts as a chemical sensor of xenobiotics [2]. In addition, it is expressed in a wide range of organs such as the small intestine, kidney, adrenals, testis, and brain [3]. Generally, it is localized in the cytoplasm in a complex with heat shock protein 90 and the CAR cytoplasmic retention protein and is translocated to the nucleus in response to the stimulation of cells by phenobarbital (PB) and other CAR activators [4] [5]. In the nucleus, CAR binds as a heterodimer with the retinoid $\mathrm{X}$ receptor $\alpha(\mathrm{RXR} \alpha)$ to CAR response element (CARE) and regulates the expression of various drug metabolizing enzymes and transporters including CYP2B6 [6], CYP3A4 [7], CYP2C9 [8], UDP-glucuronosyltransferase type 1A1 [9], sulfotransferase 2A1 [10], and ABCG2 [11].

Initial studies indicated that CAR/RXR $\alpha$ bound 5 bp-spaced direct repeats (DR5) [2]. Later studies found that CAR/RXR $\alpha$ bound DR4 motif within phenobarbital response enhancer modules (PBREMs) in a proximal promoter region of the human CYP2B6 gene and a variety of DRs [6] [12]. Moreover, CAR can also bind to everted repeat (ER) and inverted repeat (IR) arrangements [7] [10] [13] [14]. Because most known CAREs have been identified within promoter regions, CAREs at distal regions, i.e., more than $10 \mathrm{~kb}$ upstream and downstream of transcription start sites (TSS) of target genes, remain unknown. Although DNA microarray experiments have been performed to study the expression profiles of genes regulated specifically by CAR/RXR $\alpha$, microarray approaches cannot determine whether the regulated genes are primary or secondary target genes [13] [15]-[16]. Recently, genome-wide screening to identify transcription factor-binding sites, using methods such as ChIP-on-chip and ChIP-seq, has been performed against the many nuclear receptors [17]-[23]. Such a whole genome-approach has not been adopted previously for CAR/RXR $\alpha$.

We previously developed a modified yeast one-hybrid (MY1H) system that enabled rapid and efficient identification of genomic targets for DNA-binding proteins [24]. Here, using this system, we reported functional screening for CAR/RXR $\alpha$ binding sites in the human genome. We demonstrated that 108 human genomic fragments could directly interact with the CAR/RXR $\alpha$ heterodimer by electrophoretic mobility shift assays (EMSAs). Moreover, we identified 17 regulatory single nucleotide polymorphisms (rSNPs) within the identified CAR/RXR $\alpha$ binding sites.

\section{Materials and Methods}

\subsection{Plasmid Constructions}

Human RXR $\alpha$ was amplified by the polymerase chain reaction (PCR) from uterus cDNA (PCR Ready-cDNA, Maxim Biotech, Inc., San Francisco, CA, USA). This cDNA fragments were cloned into pGADT7 (CLONTECH, Mountain View, CA, USA) and reamplified by PCR with primers (Table 1, RXR $\alpha \_F$ and RXR $\alpha \_R$ ) to generate the restriction sites for subcloning. pGADT7 was cleaved with HindIII and ligated with linker DNA to remove the nuclear localization signal (NLS) and GAL4 activation domain (GAL4AD). The resulting plasmid was designated as pADH1. Then, $\mathrm{RXR} \alpha$ cDNA was inserted into pADH1 and the resulting plasmid was named pADH1_RXR $\alpha$. A foot-and-mouth disease virus (FMDV) 2A sequence was amplified by annealing synthetic oligonucleotides (Table 1, FMDV 2A_F1, and FMDV 2A_R1) and reamplified by PCR with primers (Table 1, FMDV 2A_F2, and FMDV 2A_R2) to generate the restriction sites. FMDV 2A fragment was inserted at the C-terminal end of RXR in pADH1_RXR $\alpha$ and the resulting plasmid was named pADH1_RXR $\alpha \_2 A$. The fragment including NLS-GAL4AD was amplified by PCR from pGADT7 with primers (Table 1, NLS_GAL4AD_F and NLS_GAL4AD_R) and inserted into pADH1. The resulting plasmid was named pADH1_NLS_GAL4AD. Similarly, three tandem copies of NLS_GAL4AD were inserted at pADH1 and the resulting plasmid was designated pADH1_NLS_GAL4AD $\times$ 3. Human CAR cDNA was cloned by PCR with primers (Table 1, NLS_GAL4AD_F and NLS_GAL4AD_R) from pcDNA-CAR [25] and reamplified by PCR with primers (Table 1, pADH1-hCAR_F and pADH1-hCAR_R) to generate the restriction sites for subcloning. The cDNA was inserted into pADH1_NLS_GAL4AD $\times 3$ and the resulting plasmid was named pADH1_NLS_GAL4AD $\times$ 3_ CAR. The NLS_GAL4AD $\times$ 3_CAR fragment obtained from pADH1_NLS_GAL4AD $\times$ 3_CAR was inserted at the C-terminal end of RXR $\alpha \_2 A$ in pADH1_RXR $\alpha \_2 A$ and the resulting plasmid was named pADH1 RXR $\alpha \_2 A \_N L S \_G A L 4 A D \times 3$ _CAR. pSUR (GeneBank AB425277) was constructed as previously described [24] and used as a reporter in yeast one-hybrid assays. pSUR-DR4 and pSUR-CYP2B6-NR3 were constructed 
Table 1. Primer sequences.

\begin{tabular}{|c|c|}
\hline Primer name & Sequence $\left(5^{\prime} \rightarrow 3^{\prime}\right)$ \\
\hline $\mathrm{hRXR} \alpha \_\mathrm{F}$ & AAAAAGCTTACGCGTGCCGCCACCATGGACACC \\
\hline $\mathrm{hRXR} \alpha \_\mathrm{R}$ & TTTAAGCTTTCTAGACTACTCGAGAGTCATTTGGTGCGGCGC \\
\hline FMDV-2A_F1 & AAAAGATCTTAAAATTGTCGCTCСTGTCAAACAAACTCTTAACTTTGATTTACTCAAACTGGCTG \\
\hline FMDV-2A_R1 & AAATCTAGAGGATCCTTTACTAGTTGGACCTGGATTGCTTTCTACATCCCCAGCCAGTTTGAGTAAATCA \\
\hline FMDV-2A_F2 & AAAGTCGACAAAATTGTCGCTCCTGTCAA \\
\hline FMDV-2A_R2 & TTTTCTAGAGAATTCCCGCGGCTCGAGACGCGTTGGACCTGGATTGCTTTC \\
\hline NLS-GAL4AD_F & AAAAGATCTATGGATAAAGCGGAATTAATTCCCGAGC \\
\hline NLS-GAL4AD_R & TTTCTCGAGTTTGGATCCCTCTTTTTTTGGGTTTGGTGG \\
\hline pADH1-hCAR_F & CTTGTCGACAGATCTGCCGCCACCATGGCCAGTAGGGAAGATGA \\
\hline pADH1-hCAR_R & CTTTCTAGACTACTCGAGTCAGCTGCAGATCTCCTGGAGCAGCGG \\
\hline hCAR_F & AAAGTCGACGGATCCGCCGCCACCATGGCCAGT \\
\hline hCAR_R & TTTTCTAGACTACTCGAGTCAGCTGCAGATCTCCTGGA \\
\hline dpSUR_F & AAAAAGTTATCAAGAGACTGC \\
\hline dpSUR_R & CTAATGCTTCAACTAACTCCA \\
\hline SPO13-S & CGGCTATTTCTCAATATACTCC \\
\hline Consensus DR4_F & GATCAGTTCATGGCAGTTCATGGCAGTTCAGATC \\
\hline Consensus DR4_R & GATCTGAACTGCCATGAACTGCCATGAACTGATC \\
\hline random_F & CGCGTTGTGTGTGTTTTATTCC \\
\hline random_R & GGAATAAAACACACACAACGCG \\
\hline
\end{tabular}

by inserting 3 copies of consensus DR4 [26] and 4 copies of CYP2B6 XREM-NR3 [27] upstream of the SPO13 promoter of pSUR, respectively. For in vitro transcription/translation, the cDNAs for human RXR $\alpha$ and CAR were inserted into the HindIII/Xho I site and the Sal I site of pSP64 Poly (A) (Promega, Madison, WI, USA), respectively.

\subsection{A modified Yeast One-Hybrid Assays}

The human genomic library for a modified yeast one-hybrid assay was generated as previously described [24]. The effector plasmid, pADH1_RXR $\alpha$ _2A_NLS_GAL4AD $\times$ 3_CAR, was transformed into the 5FOA-selected yeast containing the human genomic library using polyethylene glycol/lithium acetate. The obtained transformants were grown on synthetic complete media lacking leucine, tryptophan, and uracil but containing $25 \mu \mathrm{g} / \mathrm{ml}$ 6-azauracil for 3 weeks at $30^{\circ} \mathrm{C}$. Human genomic fragments were recovered from the positive colonies by colony-direct PCR with primers corresponding to the vector sequences (Table 1, dpSUR_F and dpSUR_R). The PCR fragments were directly sequenced with the primers (Table 1, SPO13-S) and used for further experiments.

\subsection{EMSAs}

The TNT SP6 High Yield system from Promega was used to prepare the human CAR and RXR $\alpha$ proteins. Double-stranded DNA probes (Table 1, consensus DR4_F and consensus DR4_R) were used with both ends labeled with Cy5. Proteins were incubated with 200 ng of calf thymus DNA (Invitrogen, Carlsbad, CA, USA) and $1 \mathrm{pmol}$ of the labeled oligonucleotide at $4^{\circ} \mathrm{C}$ in the presence or absence of the unlabeled oligonucleotides. The binding reaction was carried out in the EMSA binding buffer containing $12 \mathrm{mM}$ HEPES (pH 7.9), $60 \mathrm{mM}$ $\mathrm{KCl}, 4 \mathrm{mM} \mathrm{MgCl}{ }_{2}, 1 \mathrm{mM}$ EDTA, $12 \%$ glycerol, and $0.5 \%$ Nonidet P- 40 . The reaction mixtures were directly 
loaded onto $4 \%$ nondenaturing polyacrylamide gels made in $0.5 \times$ TBE. In the supershift experiments, CAR and $\mathrm{RXR} \alpha$ proteins were incubated with antibodies against CAR (Santa Cruz Biotechnology, Santa Cruz, CA, USA, sc-13065) or RXR $\alpha$ (Santa Cruz Biotechnology, sc-553X) overnight before incubation with the probe. After electrophoresis was performed at $4^{\circ} \mathrm{C}$, the gels were analyzed using a bio-imaging analyzer (FLA-7000 FUJIFILM). The consensus DR4 and random sequences (Table 1, random_F and random_R) were used as positive and negative controls, respectively.

\subsection{Bioinformatics}

To map the obtained sequences on the human genome assembly (GRCh37), the cloned sequences were analyzed using NCBI's BLAST and the RGKTCA motif was searched using EMBOSS fuzznuc of Galaxy

(https://usegalaxy.org/) [28]-[30]. For stringency of the search, we allowed up to 2-bp mismatches in the DR4 motif and 1-bp mismatches in the other motifs. The nearest gene and the distance from the center of the binding site to the transcriptional start site of the gene within $1000 \mathrm{~kb}$ were identified with GREAT (http://bejerano.stanford.edu/great/public/html/) [31].

\section{Results}

\subsection{Interaction between the CAR/RXR $\alpha$ Heterodimer and CARE in Yeast}

To simultaneously express CAR and RXR $\alpha$ proteins in yeast, we constructed effector plasmids by placing FMDV 2A peptide between CAR and RXR $\alpha$ [32]. Although CAR is expressed as a fusion to the NLS_GAL4AD, $\mathrm{RXR} \alpha$ was expressed as the native protein to minimize the effect of $\mathrm{RXR} \alpha$ homodimer on reporter activations (Figure 1(a)). To evaluate the function of CAR/RXR $\alpha$ heterodimer, yeast cells were transformed with these effectors and the indicated reporters (Figure 1(b)). The transformants expressing either CAR or RXR $\alpha$ alone were unable to grow, whereas the transformants expressing both CAR and RXR $\alpha$ were able to grow in a CARE-dependent manner (Figure 1(b)). The known CAR activators, CITCO [14] and PB [33] had no effect on the yeast growth in our assay conditions (data not shown). These results indicated that CAR/RXR $\alpha$ heterodimer could activate the reporter gene via CAREs.

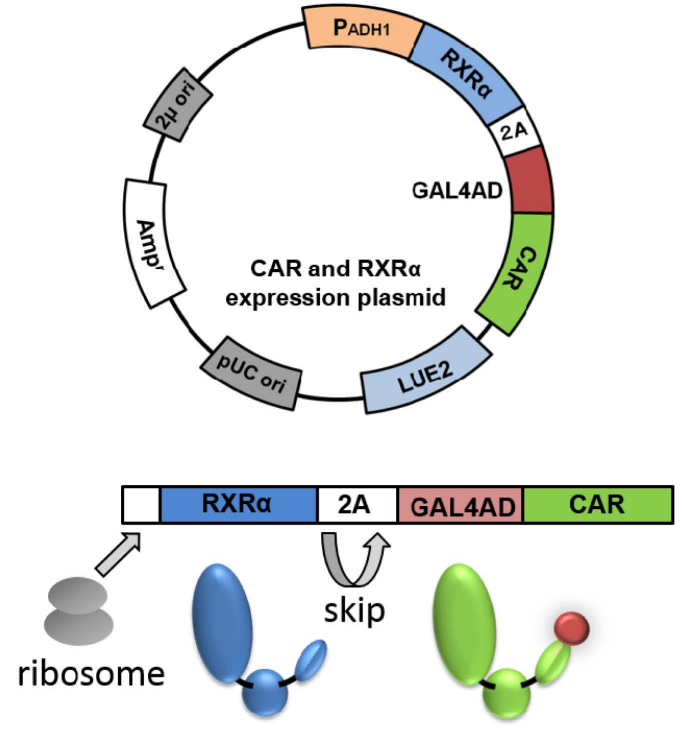

(a)

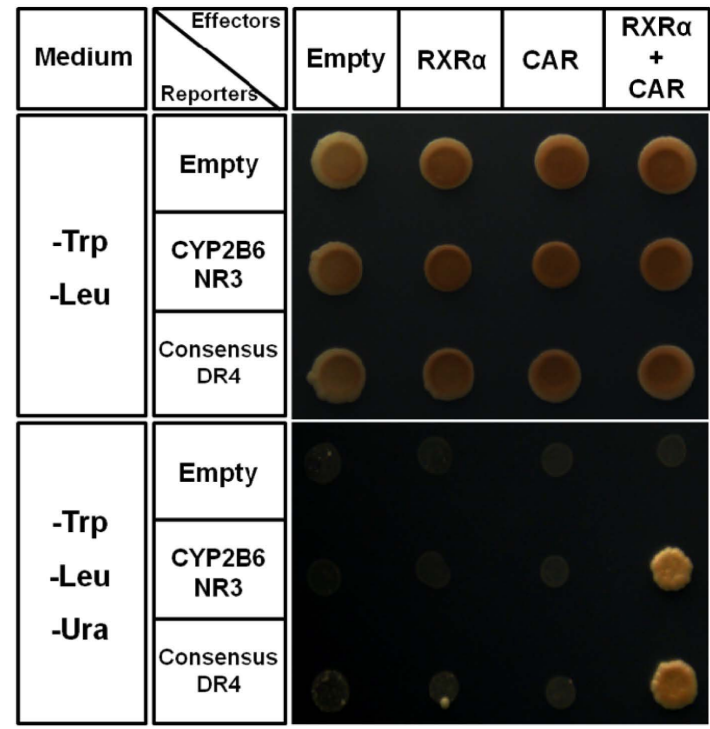

(b)

Figure 1. Yeast one-hybrid assay of the CAR/RXR $\alpha$ heterodimer. (a) Schematic diagrams of the effector plasmid. FMDV $2 \mathrm{~A}$ peptide sequence was placed between CAR and $\mathrm{RXR} \alpha$ under the control of the ADH1 promoter. CAR and RAR $\alpha$ were expressed via a 2A-mediated translational skip mechanism; (b) An examination of the CAR/RXR $\alpha$ heterodimer in yeast cells. Yeast cells were transformed with each effector and reporter plasmids and were grown on synthetic complete media lacking leucine and tryptophan (-Trp -Leu) or and lacking leucine, tryptophan, and uracil (-Trp -Leu -Ura). The plates were photographed after 4 days of growth at $30^{\circ} \mathrm{C}$. 


\subsection{Identification of CAR/RXR $\alpha$ Heterodimer-Binding Sites in the Human Genome}

The human genomic library was constructed by inserting approximately 300 bp fragments in reporter plasmids and treating with 5FOA to efficiently eliminate false-positive interactions in the yeast one-hybrid assay [24]. The CAR/RXR $\alpha$ expression plasmids were transformed into the library and more than $2.8 \times 10^{6}$ were selected on synthetic complete media lacking leucine, tryptophan, and uracil but containing $25 \mu \mathrm{g} / \mathrm{ml} 6$-azauracil. After 3 weeks, 421 positive colonies were picked from the selection plates and colony-direct PCR was performed to recover human genomic fragments. The PCR fragments were directly sequenced and 414 unique sequences were obtained. As a result of genome mapping, the majority of the 414 unique sequences were located at distal sites, far from the TSS, or in introns. Next, we performed motif enrichment among the 414 unique clones using MEME-ChIP [34]. The most frequently observed motif was a DR4 motif which is known as a classical CARE (Figure 2). Then, to obtain putative CAR/RXR $\alpha$ binding sites from the 414 unique clones, we selected these sequences based on the half-site core motif (RGKTCA). As a result, a total of 149 putative CAR/RXR $\alpha$ binding sites were obtained (Figure 3(b)). Interestingly, these sequences contained various types of elements such as DRs, ERs and IRs.

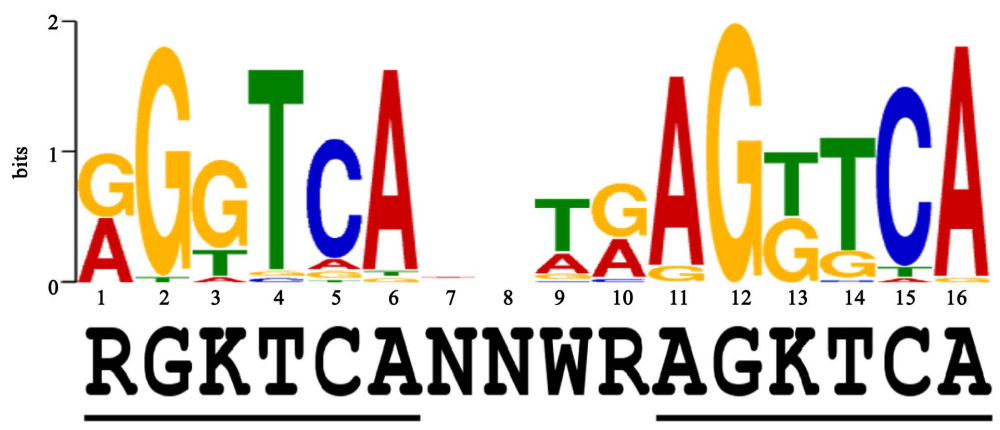

Figure 2. Motif enrichment. The most significant motifs found by MEMEChIP (http://meme.nbcr.net/meme/doc/meme-chip.html) in the clones obtained from the modified yeast one-hybrid assay. $\mathrm{E}$ value: $9.7 \times 10^{-34} . \mathrm{R}=\mathrm{A}$ or $\mathrm{G}, \mathrm{K}=\mathrm{T}$ or $\mathrm{G}, \mathrm{W}=\mathrm{A}$ or $\mathrm{T}$.

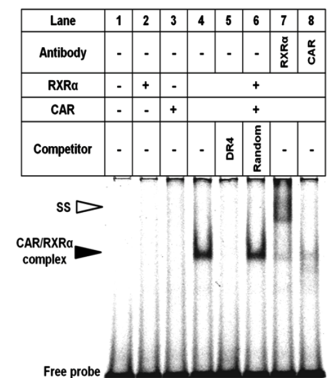

(a)

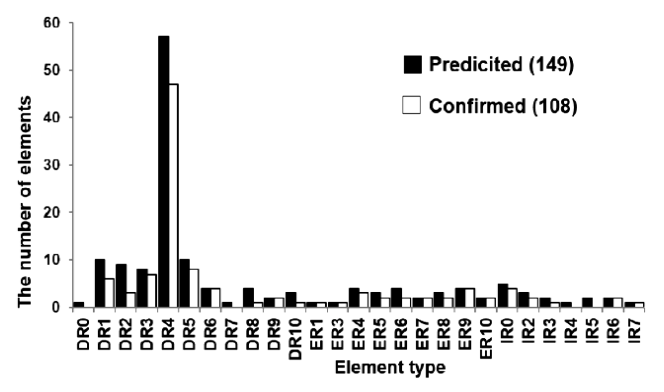

(b)

Figure 3. Validation assays for direct interactions between the CAR/RXR $\alpha$ heterodimer and the predicted elements. (a) EMSAs were performed with the in vitro-synthesized human CAR and $\mathrm{RXR} \alpha$ proteins. The proteins were incubated with 1 pmol of the Cy5-labeled consensus DR4. In a competition assay, 100-fold molar excess of the unlabeled oligonucleotides (DR4 or Random) were added to the reaction mixture. In a supershift experiment, the indicated antibodies were incubated in the reaction mixture. Closed and open arrowheads indicated the CAR/RXR $\alpha$ protein-DNA complexes and the super shifted band, respectively. (b) The number of the predicted CAR/RXR $\alpha$ binding motif and the confirmed. The predicted CAR/RXR $\alpha$ binding sites were obtained by EMBOSS fuzznuc of Galaxy based on RGKTCA motif. For the stringency of the search, motif substitution allowed up to 1-bp mismatches. Motif substitution allowed up to 2-bp mismatches only for the DR4 motif. The direct interaction was confirmed by EMSA competition assays. 


\subsection{Experimental Validation of the Putative CAR/RXR $\alpha$ Binding Sites}

To examine the direct interaction of putative CAR/RXR $\alpha$ binding sites with the CAR/RXR $\alpha$ heterodimer, we performed EMSA. Incubation of the Cy5-labeled consensus DR4 with the combination of CAR and RXR $\alpha$, but not either receptor alone, produced retarded complexes (Figure 3(a), lanes 2 - 4). The complexes represented a sequence-specific interaction between consensus DR4 and the human CAR/RXR $\alpha$ proteins, since the formation of this complex was specifically reduced with molar excess of unlabeled competitors (Figure 3(a), lanes 5 and 6). Moreover, the addition of anti-RXR $\alpha$ antibody created a slower-migrating complex and the addition of antiCAR antibody resulted in the disappearance of the band (Figure 3(a), lanes 7 and 8). No supershifted bands were observed with anti-HNF4 antibodies (data not shown). These results indicated that the sequence-specific binding complex contained both CAR and $\mathrm{RXR} \alpha$, presumably as a heterodimer.

To examine the direct interaction of CAR/RXR $\alpha$ with the 149 putative CAR/RXR $\alpha$ binding sites, we performed a semi-quantitative EMSA competition assay. In this method, it is possible to examine binding intensity using a 10- and 100-fold molar excess of unlabeled competitors. Typical examples are shown in Figure 4. Sequence I (lanes 15 - 20) was equivalent in binding intensity to the positive control (Consensus DR4, lanes 9 - 14). That is, sequence I had strong binding affinity with the CAR/RXR $\alpha$ heterodimer. In the same way, sequence II (lanes 21 - 26) had moderate binding affinity and sequence III (lanes 27 - 32) had low binding affinity. Thus, we evaluated 149 putative CAR/RXR $\alpha$ binding sites and confirmed that at least $108 \mathrm{CAR} / \mathrm{RXR} \alpha$ binding sites could directly interact with the CAR/RXR $\alpha$ heterodimer by EMSA (Table 2). These sequences contained not only classical CAREs but also a wide variety of additional arrangements.

\section{4. rSNPs in the Identified CAR/RXR $\alpha$ Binding Sites}

rSNPs in transcription factor-binding sites, which alter the ability of a transcription factor to interact with DNA, may lead to predictable differences in gene expression and may be associated with disease susceptibility. Therefore, we tried to identify rSNPs in each of the CAR/RXR $\alpha$ binding sequences using the NCBI SNP database. Thirty five rSNPs were identified and the effect on the binding affinity between CAR/RXR $\alpha$ and 35 rSNPs was examined by EMSA. As a result, 17 rSNPs were identified based on differences in the DNA-binding affinities (Table 3)

\section{Discussion}

In the present study, we identified CAR/RXR $\alpha$-binding sites in the human genome by a modified yeast one-hybrid assay. Next, we demonstrated that the 108 obtained sequences could directly interact with the CAR/RXR $\alpha$ heterodimer by EMSAs. These sequences contained not only classical CAREs but also a wide variety of arrangements (e.g., DRs, ERs, and IRs). Moreover, 17 functional rSNPs on the CAR/RXR $\alpha$ binding sites were identified by analyzing differences in DNA-binding affinity.

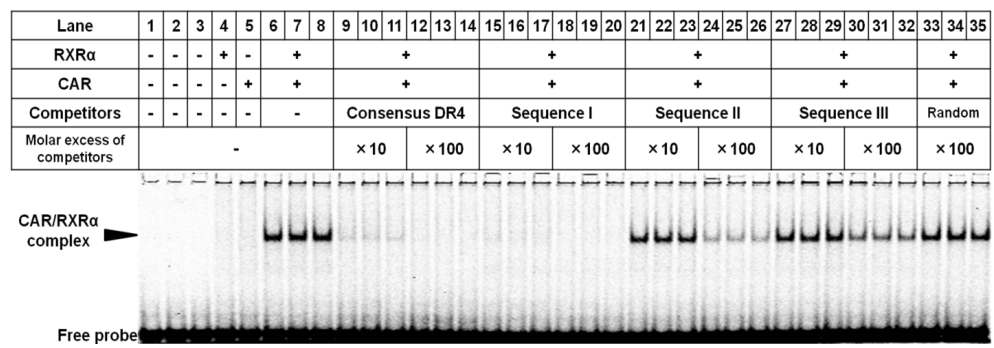

Figure 4. Typical examples of evaluation assays for the putative CAR/RXR $\alpha$ binding sites. EMSAs were performed with the in vitro-synthesized human CAR and RXR $\alpha$ proteins. The proteins were incubated with $1 \mathrm{pmol}$ of the Cy5-labeled consensus DR4. In a competition assay, 10 or 100 -fold molar excess of the unlabeled oligonucleotides were added to the reaction mixture. The closed arrowhead indicates the $\mathrm{CAR} / \mathrm{RXR} \alpha$ protein-DNA interaction. Sequence $\mathrm{I}$ is a strong binding sequence (Table 2, \#30). Sequence II is a moderate binding sequence Table 2, \#79). Sequence III is a week binding sequence (Table 2, \#89). 
Table 2. CAR/RXR $\alpha$-binding sites.

\begin{tabular}{|c|c|c|c|c|c|c|c|}
\hline \multirow{2}{*}{ \# } & \multirow{2}{*}{ Position } & \multirow{2}{*}{$\begin{array}{l}\text { Length } \\
\text { (bp) }\end{array}$} & \multirow{2}{*}{$\begin{array}{l}\text { Neighboring Gene } \\
\text { (Distance to TSS) }\end{array}$} & \multirow{2}{*}{ CAR/RXR $\alpha$ bindnig sequence } & \multirow{2}{*}{ Motif } & \multicolumn{2}{|c|}{ Competition (\%) } \\
\hline & & & & & & $\times 10$ & $\times 100$ \\
\hline 1 & $\begin{array}{c}\text { Chr18: } \\
55201286-55201390\end{array}$ & 105 & $\begin{array}{c}\text { FECH }(+52,631), \text { ONECUT2 } \\
(+98,421)\end{array}$ & tggAGTTCAaAGGTCAcat & DR1 & $14.6 \pm 1.6$ & $95.2 \pm 0.4$ \\
\hline 2 & $\begin{array}{c}\text { Chr7: } \\
\text { 138292264-138292495 }\end{array}$ & 232 & $\begin{array}{c}\text { SVOPL }(+71,410), \text { TRIM24 } \\
(+147,301)\end{array}$ & cgcAGGTCAaAGGTCAggt & DR1 & $10.7 \pm 2.2$ & $78.7 \pm 2.9$ \\
\hline 3 & $\begin{array}{c}\text { Chr5: } \\
76841961-76842018\end{array}$ & 58 & $\begin{array}{l}\text { OTP }(+92,532), \text { PDE8B } \\
(+335,284)\end{array}$ & cagAGGTCGgAGGTCAagt & DR1 & $17.9 \pm 0.5$ & $43.5 \pm 2.1$ \\
\hline 4 & $\begin{array}{c}\text { Chr20: } \\
\text { 23387626-23387738 }\end{array}$ & 113 & $\begin{array}{c}\text { NAPB }(+14,474), \text { GZF1 } \\
(+42,682)\end{array}$ & саaAGTTCAaAGGTCActg & DR1 & $52.0 \pm 1.3$ & $115.8 \pm 0.9$ \\
\hline 5 & $\begin{array}{c}\text { Chr13: } \\
\text { 59071533-59071644 }\end{array}$ & 112 & PCDH17 (+865,800) & ttaAGTGCAgGGGTCAgga & DR1 & $25.2 \pm 0.9$ & $44.6 \pm 0.8$ \\
\hline 6 & $\begin{array}{c}\text { Chr17: } \\
\text { 1918186-1918361 }\end{array}$ & 176 & $\begin{array}{l}\text { RTN4RL1 (+9,904), RPA1 } \\
\qquad(+185,001)\end{array}$ & tggAGCTCAgAGTTCAaag & DR1 & $41.4 \pm 1.8$ & $90.3 \pm 1.1$ \\
\hline 7 & $\begin{array}{c}\text { Chr4: } \\
121700806-121701088\end{array}$ & 283 & $\begin{array}{c}\text { MAD2L1 }(-712,934), \text { PRDM5 } \\
(+143,066)\end{array}$ & ttgAGGTCAagAGTTCAagg & DR2 & $30.2 \pm 2.6$ & $101.9 \pm 1.4$ \\
\hline 8 & $\begin{array}{c}\text { ChrX: } \\
\text { 40929970-40930061 }\end{array}$ & 92 & $\begin{array}{c}\text { MED14 }(-335,212), \text { USP9X } \\
(-14,872)\end{array}$ & tgtGGGTGAacAGGTCAatg & DR2 & $71.5 \pm 3.0$ & $102.7 \pm 0.3$ \\
\hline 9 & $\begin{array}{c}\text { Chr13: } \\
49397697-49397876\end{array}$ & 180 & $\begin{array}{l}\text { FNDC3A }(-152,261) \\
\text { CYSLTR2 }(+116,834)\end{array}$ & ggcGGATCAtgAGGTCAaga & DR2 & $22.2 \pm 0.8$ & $50.2 \pm 2.1$ \\
\hline 10 & $\begin{array}{c}\text { Chr17: } \\
\text { 8796437-8796604 }\end{array}$ & 168 & $\begin{array}{c}\text { PIK3R6 }(-25,527), \text { PIK3R5 } \\
(+19,313)\end{array}$ & tggAGGTCAgagAGGTCAagc & DR3 & $35.3 \pm 1.1$ & $110.3 \pm 9.6$ \\
\hline 11 & $\begin{array}{c}\text { Chr2: } \\
\text { 103266921-103267061 }\end{array}$ & 141 & $\begin{array}{c}\text { SLC9A2 }(+30,825), \text { MFSD9 } \\
(+86,346)\end{array}$ & tgaAGGTCAaagAGTTTAаса & DR3 & $56.8 \pm 0.5$ & $102.8 \pm 1.1$ \\
\hline 12 & $\begin{array}{c}\text { Chr5: } \\
142827845-142828030\end{array}$ & 186 & $\begin{array}{c}\text { NR3C1 }(-43,893), \text { YIPF5 } \\
(+722,340)\end{array}$ & cagAGGTCAcagAGGTCAtaa & DR3 & $60.0 \pm 0.6$ & $111.6 \pm 2.1$ \\
\hline 13 & $\begin{array}{c}\text { Chr7: } \\
\text { 33720609-33720751 }\end{array}$ & 143 & $\begin{array}{l}\text { BMPER }(-223,843), \text { BBS9 } \\
(+551,528)\end{array}$ & ccaAGTTCAcatAGTTCAtaa & DR3 & $65.5 \pm 0.4$ & $111.3 \pm 1.3$ \\
\hline 14 & $\begin{array}{c}\text { ChrX: } \\
\text { 45732008-45732304 }\end{array}$ & 297 & $\begin{array}{c}\text { CXorf36 }(-672,010), \text { ZNF673 } \\
(-574,468)\end{array}$ & ctgAGGCCAgggAGTTCAcca & DR3 & $35.9 \pm 2.1$ & $91.5 \pm 2.9$ \\
\hline 15 & $\begin{array}{c}\text { Chr17: } \\
54747517-54747691\end{array}$ & 175 & $\begin{array}{c}\text { NOG }(+76,544), \text { C17orf67 } \\
(+145,767)\end{array}$ & сасAGGTCAggcAGTTGAtgc & DR3 & $13.1 \pm 0.9$ & $46.9 \pm 1.9$ \\
\hline 16 & Chr6: 4942951-4943334 & 384 & $\begin{array}{c}\text { RPP40 }(+61,128), \text { CDYL } \\
(+166,463)\end{array}$ & cggAGGACAgtgGGGTCAggc & DR3 & $34.4 \pm 5.8$ & $89.6 \pm 2.6$ \\
\hline 17 & $\begin{array}{c}\text { Chr3: } \\
120575966-120576060\end{array}$ & 95 & $\begin{array}{c}\text { STXBP5L (-51,037), GTF2E1 } \\
(+114,455)\end{array}$ & taaAGGTCAaggaAGTTCAatt & DR4 & $62.8 \pm 1.3$ & $107.8 \pm 1.4$ \\
\hline 18 & $\begin{array}{c}\text { Chr12: } \\
14672183-14672322\end{array}$ & 140 & $\begin{array}{c}\text { PLBD1 }(+48,538), \text { ATF7IP } \\
(+153,642)\end{array}$ & ttaAGGTCAactgAGGTCAtat & DR4 & $51.5 \pm 1.2$ & $107.6 \pm 0.7$ \\
\hline 19 & $\begin{array}{c}\text { Chr1: } \\
220849174-220849356\end{array}$ & 183 & $\begin{array}{c}\text { C1orf115 }(-14,363), \text { MARK1 } \\
(+147,697)\end{array}$ & $\begin{array}{c}\text { gcaAGGGCAggggAGGTCAat } \\
\text { a }\end{array}$ & DR4 & $30.6 \pm 1.1$ & $77.2 \pm 0.6$ \\
\hline 20 & $\begin{array}{c}\text { Chr10: } \\
\text { 30521090-30521250 }\end{array}$ & 161 & $\begin{array}{c}\text { SVIL }(-597,269), \text { MTPAP } \\
(+117,097)\end{array}$ & agtGGATCActtgAGGTCAgga & DR4 & $20.6 \pm 0.8$ & $69.0 \pm 1.1$ \\
\hline 21 & $\begin{array}{c}\text { Chr2: } \\
55562474-55562589\end{array}$ & 116 & $\begin{array}{c}\text { MTIF2 }(-66,148), \text { CCDC88A } \\
(+84,525)\end{array}$ & gtgAGGTCAttaaAGTTCAtgt & DR4 & $70.8 \pm 0.8$ & $112.6 \pm 0.4$ \\
\hline 22 & Chr8: 1165688-1165800 & 113 & $\begin{array}{c}\text { C8orf42 }(-670,413), \text { DLGAP2 } \\
(-283,825)\end{array}$ & atgGGTTCAtttgGGTGCAtca & DR4 & $50.1 \pm 0.7$ & $104.2 \pm 0.0$ \\
\hline 23 & $\begin{array}{c}\text { Chr13: } \\
91370194-91370452\end{array}$ & 259 & GPC5 $(-680,612)$ & ctgGGGTCAtatgATTTCAtag & DR4 & $41.2 \pm 1.2$ & $93.4 \pm 0.8$ \\
\hline 24 & $\begin{array}{c}\text { Chr3: } \\
\text { 177287827-177287945 }\end{array}$ & 119 & $\begin{array}{l}\text { KCNMB2 (-966,338), } \\
\text { TBL1XR1 (-372,838) }\end{array}$ & ttaGGGTCAgctgAGTTCAtat & DR4 & $61.5 \pm 1.9$ & $100.8 \pm 1.3$ \\
\hline 25 & $\begin{array}{c}\text { Chr6: } \\
42700810-42701034\end{array}$ & 225 & $\begin{array}{c}\text { PRPH2 }(-10,564), \text { TBCC } \\
(+12,962)\end{array}$ & tcaAGGTTAcaagAGTTCAaga & DR4 & $75.4 \pm 0.2$ & $127.9 \pm 4.5$ \\
\hline
\end{tabular}




\section{Continued}

\begin{tabular}{|c|c|c|c|c|c|c|c|}
\hline 26 & $\begin{array}{c}\text { ChrX: } \\
\text { 66743819-66744135 }\end{array}$ & 317 & $\begin{array}{c}\text { EDA2R }(-908,105), \text { AR } \\
(-19,897)\end{array}$ & gagAGGTCAatgaGGTTCAcag & DR4 & $49.7 \pm 0.8$ & $99.8 \pm 0.7$ \\
\hline 27 & $\begin{array}{c}\text { Chr9: } \\
\text { 13275072-13275351 }\end{array}$ & 280 & MPDZ $(-24,841)$ & taaAGGTTAaatgAGGTCActa & DR4 & $53.2 \pm 0.8$ & $104.7 \pm 1.6$ \\
\hline 28 & $\begin{array}{c}\text { Chr19: } \\
\text { 5982545-5982685 }\end{array}$ & 141 & RANBP3 (-4295) & tcaAGTTCAtgaaAGGTCAcac & DR4 & $61.7 \pm 1.3$ & $114.6 \pm 0.6$ \\
\hline 29 & $\begin{array}{c}\text { Chr5: } \\
\text { 168554759-168554923 }\end{array}$ & 165 & $\begin{array}{c}\text { PANK3 }(-548,227), \text { SLIT3 } \\
(+173,292)\end{array}$ & caaAGTTCActtaAGTTCAgag & DR4 & $57.6 \pm 0.7$ & $116.7 \pm 0.7$ \\
\hline 30 & Chr8: 4846264-4846562 & 299 & CSMD1 (+5915) & caaAGGTCActtaAGGTCAttt & DR4 & $71.4 \pm 1.5$ & $125.1 \pm 1.1$ \\
\hline 31 & $\begin{array}{c}\text { Chr1: } \\
\text { 88626432-88626556 }\end{array}$ & 125 & $\begin{array}{c}\text { PKN2 }(-523,428), \text { LMO4 } \\
(+832,343)\end{array}$ & tttAGGTCAttgaAGTTCAagt & DR4 & $55.4 \pm 0.7$ & $106.2 \pm 3.5$ \\
\hline 32 & $\begin{array}{c}\text { Chr8: } \\
\text { 95584473-95584707 }\end{array}$ & 235 & $\begin{array}{c}\text { ESRP1 }(-68,774), \\
\text { KIAA1429 }(-18,844)\end{array}$ & aagAGGTCAgttgGGGTCAgat & DR4 & $45.0 \pm 1.3$ & $99.8 \pm 1.3$ \\
\hline 33 & $\begin{array}{c}\text { Chr7: } \\
\text { 15597442-15597713 }\end{array}$ & 272 & $\begin{array}{c}\text { DGKB }(-716,503), \text { AGMO } \\
(+4062)\end{array}$ & caaAGGGCAccagAGTTAAcag & DR4 & $23.9 \pm 1.6$ & $67.6 \pm 0.8$ \\
\hline 34 & $\begin{array}{c}\text { Chr14: } \\
54345870-54346006\end{array}$ & 137 & $\begin{array}{c}\text { DDHD1 }(-725,892), \text { BMP4 } \\
(+75,332)\end{array}$ & ctgAGGTCAagtgAGTTCAcct & DR4 & $70.2 \pm 0.9$ & $118.5 \pm 1.4$ \\
\hline 35 & $\begin{array}{c}\text { Chr15: } \\
\text { 49543989-49544276 }\end{array}$ & 288 & $\begin{array}{c}\text { FGF7 }(-171,242), \text { GALK2 } \\
(+81,711)\end{array}$ & ggtGGATCActtgAGGTCAgga & DR4 & $26.0 \pm 2.4$ & $65.0 \pm 0.7$ \\
\hline 36 & $\begin{array}{c}\text { Chr13: } \\
\text { 55084028-55084114 }\end{array}$ & 87 & NONE & atgGGGTCAacaaAGTTTAaga & DR4 & $83.3 \pm 4.9$ & $119.2 \pm 5.2$ \\
\hline 37 & $\begin{array}{c}\text { Chr8: } \\
\text { 112300235-112300383 }\end{array}$ & 149 & NONE & aagAGGTTAcaagAGTTCAtat & DR4 & $69.2 \pm 1.1$ & $112.9 \pm 0.3$ \\
\hline 38 & $\begin{array}{c}\text { Chr3: } \\
\text { 28008615-28008785 }\end{array}$ & 171 & $\begin{array}{c}\text { CMC1 }(-274,424), \text { EOMES } \\
(-244,915)\end{array}$ & gtgGGGTCAcatgAGGGCAcat & DR4 & $51.9 \pm 1.8$ & $105.3 \pm 1.0$ \\
\hline 39 & $\begin{array}{c}\text { Chr15: } \\
\text { 87420670-87420730 }\end{array}$ & 61 & AGBL1 $(+735,458)$ & aagAGGTCAactgAGTTCAtcc & DR4 & $69.2 \pm 0.6$ & $114.4 \pm 0.3$ \\
\hline 40 & $\begin{array}{c}\text { Chr9: } \\
\text { 81575106-81575356 }\end{array}$ & 251 & $\begin{array}{l}\text { TLE4 }(-611,647), \text { PSAT1 } \\
(+663,172)\end{array}$ & aggAGGTGAtaaaGGTTAAatg & DR4 & $21.0 \pm 1.5$ & $64.6 \pm 0.5$ \\
\hline 41 & $\begin{array}{c}\text { Chr15: } \\
\text { 65168224-65168305 }\end{array}$ & 82 & $\begin{array}{c}\text { PIF1 (-50,427), ANKDD1A } \\
(-35,836)\end{array}$ & atgGTGTCAgaagAGTTCAtca & DR4 & $64.7 \pm 0.6$ & $107.5 \pm 0.2$ \\
\hline 42 & $\begin{array}{c}\text { Chr10: } \\
\text { 31605586-31605754 }\end{array}$ & 169 & ZEB1 (-2431) & aaaAGGTGAacagAGTTCAttg & DR4 & $73.5 \pm 1.4$ & $113.6 \pm 1.0$ \\
\hline 43 & Chr4: 4003949-4004240 & 292 & $\begin{array}{l}\text { OTOP1 }(+224,526) \\
\text { ADRA2C }(+235,799)\end{array}$ & atgGGGTCAgctaGGTTTActt & DR4 & $43.3 \pm 0.8$ & $100.1 \pm 2.4$ \\
\hline 44 & $\begin{array}{c}\text { Chr5: } \\
\text { 154114732-154114879 }\end{array}$ & 148 & $\begin{array}{l}\text { LARP1 }(+22,344), \text { C5orf4 } \\
(+115,407)\end{array}$ & ggcAGGTCAcctgAGGTCAgga & DR4 & $34.2 \pm 1.1$ & $97.2 \pm 0.3$ \\
\hline 45 & $\begin{array}{c}\text { Chr15: } \\
\text { 69230539-69230630 }\end{array}$ & 92 & $\begin{array}{c}\text { NOX5 }(-76,449), \text { SPESP1 } \\
(+7746)\end{array}$ & ggtGGGTCAactaAGGTCAgga & DR4 & $50.2 \pm 3.9$ & $100.7 \pm 0.9$ \\
\hline 46 & $\begin{array}{c}\text { Chr8: } \\
\text { 140124212-140124570 }\end{array}$ & 359 & $\begin{array}{l}\text { COL22A1 }(-198,155), \\
\text { KCNK9 }(+590,908)\end{array}$ & gccAGTGCAgaagAGGTCAсас & DR4 & $27.7 \pm 2.0$ & $78.3 \pm 0.9$ \\
\hline 47 & $\begin{array}{c}\text { Chr8: } \\
\text { 107263662-107263790 }\end{array}$ & 129 & $\begin{array}{c}\text { OXR1 }(-196,426), \text { ZFPM2 } \\
(+932,579)\end{array}$ & gtcGGGTCActtaAGGTCAgga & DR4 & $40.7 \pm 0.4$ & $95.7 \pm 0.9$ \\
\hline 48 & $\begin{array}{c}\text { Chr15: } \\
78475549-78475775\end{array}$ & 227 & $\begin{array}{c}\text { IDH3A }(+33,943), \text { ACSBG1 } \\
(+51,387)\end{array}$ & ggaGGGTCAtttgAGGTCAgga & DR4 & $39.3 \pm 0.8$ & $98.1 \pm 2.7$ \\
\hline 49 & $\begin{array}{c}\text { Chr14: } \\
\text { 65099982-65100056 }\end{array}$ & 75 & $\begin{array}{l}\text { PLEKHG3 }(-94,292), \\
\text { HSPA2 }(+92,833)\end{array}$ & attAGTTAAgatgAGGTCAtac & DR4 & $19.3 \pm 5.4$ & $62.2 \pm 5.6$ \\
\hline 50 & $\begin{array}{c}\text { Chr6: } \\
\text { 31790280-31790663 }\end{array}$ & 384 & $\begin{array}{c}\text { HSPA1B }(-5040), \text { HSPA1A } \\
(+7181)\end{array}$ & caaGGATCAaagaAGTTCAgtg & DR4 & $57.1 \pm 1.0$ & $88.6 \pm 0.2$ \\
\hline 51 & $\begin{array}{c}\text { Chr13: } \\
90222946-90223063\end{array}$ & 118 & NONE & gtaAGGTCAtaaaAGTTCAggt & DR4 & $63.1 \pm 1.8$ & $110.6 \pm 0.4$ \\
\hline 52 & $\begin{array}{c}\text { ChrX: } \\
132353555-132353667\end{array}$ & 113 & TFDP3 (-1235) & ttaAGGTTAaatgAGGTCAtaa & DR4 & $55.1 \pm 0.2$ & $97.8 \pm 0.4$ \\
\hline
\end{tabular}




\section{Continued}

\begin{tabular}{|c|c|c|c|c|c|c|c|}
\hline 53 & $\begin{array}{c}\text { Chr12: } \\
\text { 80739933-80740212 }\end{array}$ & 280 & $\begin{array}{c}\text { PTPRQ (-98,053), OTOGL } \\
(+136,840)\end{array}$ & caaGGTTGAttagAGTTCAgcc & DR4 & $48.2 \pm 1.3$ & $93.5 \pm 0.3$ \\
\hline 54 & $\begin{array}{c}\text { Chr6: } \\
\text { 133030154-133030300 }\end{array}$ & 147 & $\begin{array}{c}\text { TAAR1 }(-63,085), \text { VNN1 } \\
(+4967)\end{array}$ & aaaAGGTCGtctgAGGGCAtca & DR4 & $37.7 \pm 2.3$ & $89.0 \pm 0.3$ \\
\hline 55 & $\begin{array}{c}\text { Chr20: } \\
38461220-38461351\end{array}$ & 132 & $\begin{array}{c}\text { MAFB }(+856,590), \text { DHX35 } \\
(+870,305)\end{array}$ & acaGGGTCAcaaaAGGCCAata & DR4 & $34.3 \pm 0.2$ & $88.9 \pm 1.6$ \\
\hline 56 & Chr18: 609485-609841 & 357 & $\begin{array}{c}\text { CLUL1 (-7037), CETN1 } \\
(+29,294)\end{array}$ & ggtGGGTCAtttgAGGTCAgga & DR4 & $41.9 \pm 1.1$ & $96.9 \pm 0.6$ \\
\hline 57 & $\begin{array}{c}\text { Chr4: } \\
4081417-4081706\end{array}$ & 290 & $\begin{array}{c}\text { OTOP1 }(+147,059), \text { ADRA2C } \\
(+313,266)\end{array}$ & ggcGGATCActtgAGGTCAgga & DR4 & $17.5 \pm 1.0$ & $60.6 \pm 0.7$ \\
\hline 58 & $\begin{array}{c}\text { Chr4: } \\
27697777-27697856\end{array}$ & 80 & STIM2 $(+835,504)$ & gggAGGTCActcaAGTTCActg & DR4 & $66.1 \pm 1.5$ & $114.3 \pm 1.4$ \\
\hline 59 & $\begin{array}{c}\text { Chr11: } \\
\text { 70447681-70447959 }\end{array}$ & 279 & $\begin{array}{c}\text { CTTN }(+203,208), \text { SHANK2 } \\
(+488,022)\end{array}$ & ggtGGATCAcctgAGGTCAgga & DR4 & $17.5 \pm 0.9$ & $55.7 \pm 2.6$ \\
\hline 60 & $\begin{array}{c}\text { Chr17: } \\
\text { 71023806-71024052 }\end{array}$ & 247 & $\begin{array}{c}\text { SLC39A11 }(+64,924), \text { SOX9 } \\
(+906,768)\end{array}$ & caaGGGTCAaatcAGGGCActg & DR4 & $40.6 \pm 1.4$ & $102.2 \pm 0.3$ \\
\hline 61 & $\begin{array}{c}\text { Chr7: } \\
\text { 87875231-87875351 }\end{array}$ & 121 & $\begin{array}{c}\text { SRI }(-25,898), \text { STEAP4 } \\
(+60,937)\end{array}$ & caaAGGTTAcaagAGTTCTctt & DR4 & $60.4 \pm 1.4$ & $96.3 \pm 1.8$ \\
\hline 62 & $\begin{array}{c}\text { Chr2: } \\
\text { 89376298-89376461 }\end{array}$ & 164 & RPIA $(+385,204)$ & caaAGGTTAccttAGGTCAtat & DR4 & $36.9 \pm 1.5$ & $92.5 \pm 1.1$ \\
\hline 63 & $\begin{array}{c}\text { Chr2: } \\
95707549-95707691\end{array}$ & 143 & $\begin{array}{c}\text { MAL }(+16,141), \text { MRPS5 } \\
(+80,134)\end{array}$ & gggGGGTTAgcagAGTTGAgct & DR4 & $33.8 \pm 3.4$ & $76.2 \pm 5.0$ \\
\hline 64 & $\begin{array}{c}\text { Chr4: } \\
\text { 88898879-88898955 }\end{array}$ & 77 & $\begin{array}{c}\text { PKD2 }(-29,882), \text { SPP1 } \\
(+2,115)\end{array}$ & cagAGTTCAattccAGTTGAaca & DR5 & $17.6 \pm 2.2$ & $73.4 \pm 0.3$ \\
\hline 65 & $\begin{array}{c}\text { Chr1: } \\
\text { 177083927-177084138 }\end{array}$ & 212 & $\begin{array}{c}\text { ASTN1 }(+49,991), \text { PAPPA2 } \\
(+651,726)\end{array}$ & gctGGGTCAggaaaAGTTCAtgg & DR5 & $69.6 \pm 9.1$ & $98.0 \pm 0.2$ \\
\hline 66 & $\begin{array}{c}\text { Chr6: } \\
\text { 133330363-133330649 }\end{array}$ & 287 & $\begin{array}{c}\text { EYA4 }(-231,989), \text { RPS12 } \\
(+194,798)\end{array}$ & agtGGTTCAatcacAGTTCActg & DR5 & $49.6 \pm 0.2$ & $89.9 \pm 1.0$ \\
\hline 67 & $\begin{array}{c}\text { Chr14: } \\
\text { 35253086-35253208 }\end{array}$ & 123 & $\begin{array}{c}\text { CFL2 }(-69,118), \text { BAZ1A } \\
(+91,706)\end{array}$ & aaaAGTTCAaасасAGTTCAttt & DR5 & $71.6 \pm 1.9$ & $109.9 \pm 0.9$ \\
\hline 68 & $\begin{array}{c}\text { Chr1: } \\
84080031-84080193\end{array}$ & 163 & TTLL7 $(+384,721)$ & aagAGGTCAagtcaGGTACAaас & DR5 & $37.2 \pm 0.7$ & $86.4 \pm 1.0$ \\
\hline 69 & $\begin{array}{c}\text { Chr5: } \\
\text { 89560627-89560695 }\end{array}$ & 69 & CETN3 (+144,942) & aggAGGTCAggaggAGTTCActg & DR5 & $67.0 \pm 2.5$ & $102.2 \pm 0.8$ \\
\hline 70 & $\begin{array}{c}\text { ChrX: } \\
\text { 36376152-36376213 }\end{array}$ & 62 & $\begin{array}{c}\text { PRRG1 (-832,345), CXorf59 } \\
(+311,130)\end{array}$ & aggAGGTCAatatgAGGTCAcag & DR5 & $39.2 \pm 0.3$ & $95.8 \pm 1.2$ \\
\hline 71 & $\begin{array}{c}\text { Chr1: } \\
48570878-48571087\end{array}$ & 210 & $\begin{array}{c}\text { SLC5A9 (-117,374), } \\
\text { LOC388630 }(-108,421)\end{array}$ & gaaAGGTCActcagAGTTCAttt & DR5 & $68.6 \pm 9.7$ & $120.4 \pm 0.4$ \\
\hline 72 & $\begin{array}{c}\text { Chr10: } \\
16445680-16445852\end{array}$ & 173 & $\begin{array}{c}\text { FAM188A }(-543,247), \text { PTER } \\
(-33,201)\end{array}$ & taaAGTTCAtggtaaAGTTCAtgg & DR6 & $74.0 \pm 1.2$ & $119.3 \pm 0.6$ \\
\hline 73 & $\begin{array}{c}\text { Chr4: } \\
\text { 80819846-80819929 }\end{array}$ & 84 & $\begin{array}{c}\text { GK2 }(-490,516), \text { ANTXR2 } \\
(+174,589)\end{array}$ & gaaAGTTCAtattgtAGGTCAttc & DR6 & $64.7 \pm 1.0$ & $112.9 \pm 1.4$ \\
\hline 74 & $\begin{array}{c}\text { Chr2: } \\
\text { 33407228-33407375 }\end{array}$ & 148 & $\begin{array}{c}\text { RASGRP3 }(-331,640), \text { LTBP1 } \\
(+234,933)\end{array}$ & ctaAGTTCAtgatagAGTTCAaag & DR6 & $65.3 \pm 1.3$ & $112.5 \pm 1.2$ \\
\hline 75 & $\begin{array}{c}\text { Chr6: } \\
\text { 23048624-23048748 }\end{array}$ & 125 & PRL $(-745,604)$ & ttgAGCTCAattcctAGTTCAcca & DR6 & $27.2 \pm 0.8$ & $74.3 \pm 0.8$ \\
\hline 76 & $\begin{array}{c}\text { Chr2: } \\
135675135-135675350\end{array}$ & 216 & CCNT2 (-1149) & ttgAGGTCAggagttcgAGGGCAagg & DR8 & $11.7 \pm 1.0$ & $54.8 \pm 2.6$ \\
\hline 77 & $\begin{array}{c}\text { Chr20: } \\
\text { 36825053-36825172 }\end{array}$ & 120 & $\begin{array}{c}\text { BPI (-107,439), TGM2 } \\
(-31,413)\end{array}$ & ctgGGGTCAcagggccagAGGTCActg & DR9 & $18.8 \pm 3.0$ & $70.2 \pm 3.6$ \\
\hline 78 & $\begin{array}{c}\text { Chr21: } \\
34190796-34190941\end{array}$ & 146 & C21orf62 (-4816) & tagGGGTCAcctcggtagGGGTCAggg & DR9 & $17.9 \pm 0.6$ & $58.7 \pm 0.7$ \\
\hline 79 & $\begin{array}{c}\text { Chr1: } \\
\text { 154209880-154209999 }\end{array}$ & 120 & $\begin{array}{c}\text { HAX1 }(-35,099), \text { UBAP2L } \\
(+16,615)\end{array}$ & tcaGGGTCAaacaatgctgAGTTCAaat & DR10 & $34.4 \pm 1.2$ & $90.0 \pm 0.6$ \\
\hline 80 & $\begin{array}{c}\text { Chr14: } \\
98635538-98635762\end{array}$ & 225 & NONE & gacTGAACTcTGGTCAttt & ER1 & $13.0 \pm 5.0$ & $58.3 \pm 3.2$ \\
\hline 81 & $\begin{array}{c}\text { Chr12: } \\
34343448-34343791\end{array}$ & 344 & ALG10 (+168,404) & tggTGCCCTcctAGGTCAtgg & ER3 & $37.6 \pm 0.8$ & $41.6 \pm 4.5$ \\
\hline
\end{tabular}




\section{Continued}

\begin{tabular}{|c|c|c|c|c|c|c|c|}
\hline 82 & $\begin{array}{c}\text { Chr12: } \\
10876774-10876871\end{array}$ & 98 & CSDA $(-870)$ & attTGGCCCctagGGTTCAgac & ER4 & $19.6 \pm 0.2$ & $42.6 \pm 0.6$ \\
\hline 83 & $\begin{array}{c}\text { Chr9: } \\
\text { 130011528-130011906 }\end{array}$ & 379 & $\begin{array}{l}\text { ANGPTL2 (-126,673), } \\
\text { GARNL3 (-15,039) }\end{array}$ & tctTGAACTcctgGGCTCAagt & ER4 & $4.4 \pm 2.5$ & $55.2 \pm 0.9$ \\
\hline 84 & $\begin{array}{c}\text { Chr10: } \\
\text { 58646226-58646342 }\end{array}$ & 117 & ZWINT $(-525,250)$ & ctgTGACCTcttgAGAACTtaa & ER4 & $19.7 \pm 0.5$ & $81.6 \pm 1.7$ \\
\hline 85 & $\begin{array}{c}\text { Chr20: } \\
7438451-7438525\end{array}$ & 75 & $\begin{array}{c}\text { HAO1 }(+482,605), \text { BMP2 } \\
(+689,743)\end{array}$ & acaTGAACTtttggAGGTCAtat & ER5 & $78.2 \pm 0.5$ & $115.0 \pm 0.4$ \\
\hline 86 & $\begin{array}{c}\text { Chr1: } \\
\text { 242533417-242533615 }\end{array}$ & 199 & $\begin{array}{c}\text { MAP1LC3C }(-371,131), \text { PLD5 } \\
(+154,482)\end{array}$ & caaGGAACTaaataAGTTCAttt & ER5 & $30.9 \pm 1.1$ & $75.6 \pm 0.9$ \\
\hline 87 & $\begin{array}{c}\text { Chr1: } \\
\text { 219789689-219789818 }\end{array}$ & 130 & $\begin{array}{l}\text { SLC30A10 (+312,239), } \\
\text { LYPLAL1 (+442,562) }\end{array}$ & atgTGAACTcttctaAGTTCAtgg & ER6 & $79.0 \pm 0.7$ & $111.1 \pm 0.7$ \\
\hline 88 & $\begin{array}{c}\text { Chr9: } \\
46385533-46385719\end{array}$ & 187 & NONE & gtgTGACCTttttaaAGTTAAatt & ER6 & $26.9 \pm 2.5$ & $87.2 \pm 1.4$ \\
\hline 89 & $\begin{array}{c}\text { Chr3: } \\
74240550-74240667\end{array}$ & 118 & $\begin{array}{c}\text { PDZRN3 }(-566,537), \text { CNTN3 } \\
(+329,734)\end{array}$ & aacTGACCCattttcaGGTTCActg & ER7 & $30.0 \pm 4.9$ & $53.0 \pm 2.5$ \\
\hline 90 & $\begin{array}{c}\text { Chr8: } \\
41543991-41544261\end{array}$ & 271 & $\begin{array}{c}\text { NKX6-3 }(-39,251), \text { ANK1 } \\
(+210,154)\end{array}$ & tgcTGACCTtgctgagAGTTCAtgt & ER7 & $66.1 \pm 0.2$ & $101.5 \pm 0.5$ \\
\hline 91 & $\begin{array}{c}\text { Chr6: } \\
\text { 108964946-108965090 }\end{array}$ & 145 & $\begin{array}{c}\text { ARMC2 }(-204,601), \text { FOXO3 } \\
(+82,949)\end{array}$ & agcTGAACTctgcactaAGGTCAgat & ER8 & $65.3 \pm 1.6$ & $103 \pm 0.3$ \\
\hline 92 & $\begin{array}{c}\text { Chr14: } \\
91348266-91348370\end{array}$ & 105 & $\begin{array}{c}\text { TTC7B }(-65,557), \text { RPS6KA5 } \\
(+178,675)\end{array}$ & gatTAAACTctaatcaaAGGTCAaag & ER8 & $76.5 \pm 1.2$ & $106.7 \pm 3.1$ \\
\hline 93 & $\begin{array}{c}\text { Chr20: } \\
1565505-1565776\end{array}$ & 272 & $\begin{array}{c}\text { SIRPD }(-27,298), \text { SIRPB1 } \\
(+35,048)\end{array}$ & tctTGACCCttttgtcaaAGGTCAatt & ER9 & $58.9 \pm 1.5$ & $101.4 \pm 0.6$ \\
\hline 94 & $\begin{array}{c}\text { Chr18: } \\
\text { 66213526-66213902 }\end{array}$ & 377 & TMX3 $(+168,639)$ & tttTGAACTctgtctgaaAGGTCActt & ER9 & $72.2 \pm 1.5$ & $105.3 \pm 0.5$ \\
\hline 95 & $\begin{array}{c}\text { Chr1: } \\
42946546-42946764\end{array}$ & 219 & $\begin{array}{c}\text { PPIH }(-177,393), \text { PPCS } \\
(+24,482)\end{array}$ & ggaTGACCTgaggccaggAGTTCAaga & ER9 & $54.4 \pm 0.4$ & $96.9 \pm 1.5$ \\
\hline 96 & $\begin{array}{c}\text { Chr5: } \\
\text { 88641418-88641561 }\end{array}$ & 144 & MEF2C $(-441,568)$ & accTTAACTctgtctggaAGGTCAaga & ER9 & $21.9 \pm 1.0$ & $79.5 \pm 1.9$ \\
\hline 97 & $\begin{array}{c}\text { Chr5: } \\
\text { 54048617-54048892 }\end{array}$ & 276 & $\begin{array}{c}\text { ESM1 }(+232,659), \text { SNX18 } \\
(+235,162)\end{array}$ & agaTGACCTctgcccgctaAGTTCAagt & ER10 & $53.4 \pm 1.5$ & $111.2 \pm 0.8$ \\
\hline 98 & $\begin{array}{c}\text { Chr17: } \\
22251179-22251327\end{array}$ & 149 & MTRNR2L1 $(+228,816)$ & accTGAACTttcaaaggaaGGTTCAatt & ER10 & $31.8 \pm 1.0$ & $101.7 \pm 1.7$ \\
\hline 99 & $\begin{array}{c}\text { Chr21: } \\
42948507-42948610\end{array}$ & 104 & $\begin{array}{c}\text { TMPRSS2 }(-68,567), \text { RIPK4 } \\
(+238,690)\end{array}$ & tggAGTTCATGACCTtgt & IR0 & $50.8 \pm 2.9$ & $126.6 \pm 2.0$ \\
\hline 100 & $\begin{array}{c}\text { Chr22: } \\
\text { 51188718-51188943 }\end{array}$ & 226 & $\begin{array}{c}\text { ACR }(+12,179), \text { RABL2B } \\
(+33,256)\end{array}$ & caaAGGACATGAACTctt & IR0 & $6.4 \pm 1.0$ & $52.9 \pm 1.1$ \\
\hline 101 & $\begin{array}{c}\text { Chr5: } \\
\text { 113265138-113265327 }\end{array}$ & 190 & $\begin{array}{c}\text { KCNN2 }(-432,783), \text { YTHDC2 } \\
(+415,842)\end{array}$ & atgAGTTCATGTCCTttg & IR0 & $19.2 \pm 2.8$ & $72.2 \pm 3.0$ \\
\hline 102 & $\begin{array}{c}\text { Chr19: } \\
27990058-27990456\end{array}$ & 399 & NONE & caaAGGACATGAACTcat & IR0 & $20.4 \pm 2.7$ & $65.6 \pm 0.7$ \\
\hline 103 & $\begin{array}{c}\text { Chr3: } \\
\text { 135695587-135695826 }\end{array}$ & 240 & $\begin{array}{c}\text { PPP2R3A }(+11,192), \text { MSL2 } \\
(+218,981)\end{array}$ & ttaAGTTCAtcTGAAATtta & IR2 & $15.9 \pm 2.3$ & $46.0 \pm 1.5$ \\
\hline 104 & $\begin{array}{c}\text { Chr16: } \\
\text { 27714860-27714998 }\end{array}$ & 139 & $\begin{array}{c}\text { GTF3C1 }(-153,678), \text { GSG1L } \\
(+359,901)\end{array}$ & cttAGTTCAgcTGACCTctg & IR2 & $48.7 \pm 2.4$ & $116.6 \pm 1$ \\
\hline 105 & $\begin{array}{c}\text { Chr14: } \\
58472137-58472540\end{array}$ & 404 & $\begin{array}{l}\text { SLC35F4 }(-139,747), \\
\text { C14orf37 }(+146,508)\end{array}$ & aggAGGTCAaagTGTCCTctg & IR3 & $8.8 \pm 6.8$ & $54.4 \pm 6.9$ \\
\hline 106 & $\begin{array}{c}\text { Chr7: } \\
\text { 152388241-152388469 }\end{array}$ & 229 & $\begin{array}{c}\text { ACTR3B }(-68,496), \text { XRCC2 } \\
(-15,105)\end{array}$ & tggAGTTCAttggcaTGACCTcgg & IR6 & $12.4 \pm 3.7$ & $85.6 \pm 1.3$ \\
\hline 107 & $\begin{array}{c}\text { Chr5: } \\
\text { 162859214-162859417 }\end{array}$ & 204 & CCNG1 (-5261) & taaAGGTCAttgcctTAACCTagg & IR6 & $16.1 \pm 1.2$ & $70.0 \pm 1.1$ \\
\hline 108 & $\begin{array}{c}\text { Chr18: } \\
\text { 30395764-30395944 }\end{array}$ & 181 & $\begin{array}{c}\text { ASXL3 }(-762,687), \text { KLHL14 } \\
(-42,880)\end{array}$ & aаaAGTTCAacctcccTTAACTatg & IR7 & $32.9 \pm 1.4$ & $95.7 \pm 0.8$ \\
\hline
\end{tabular}


Table 3. rSNPs in the identified CAR/RXR $\alpha$ binding sites.

\begin{tabular}{|c|c|c|c|c|c|}
\hline dbSNP & Gene (Distance to TSS) & Sequences & Motif & $\begin{array}{c}\text { Concentration of } \\
\text { competitor }\end{array}$ & $\begin{array}{c}\text { EMSA } \\
\text { Competition (\%) }\end{array}$ \\
\hline rs115089792 & NONE & $\begin{array}{l}\text { atgGGGTCAасаaAGTTTAaga } \\
\text { atgGTGTCAacaaAGTTTAaga }\end{array}$ & DR4 & $\times 10$ & $\begin{array}{l}62.8 \pm 0.6 \\
36.0 \pm 0.4\end{array}$ \\
\hline rs371021620 & $\begin{array}{c}\text { FAM188A }(-543,247), \text { PTER } \\
(-33,201)\end{array}$ & $\begin{array}{l}\text { taaAGTTCAtggtaaAGTTCAtgg } \\
\text { taaAATTCAtggtaaAGTTCAtgg }\end{array}$ & DR6 & $\times 10$ & $\begin{array}{l}64.0 \pm 1.1 \\
19.4 \pm 0.8\end{array}$ \\
\hline rs62097972 & TMX3 $(+168,639)$ & $\begin{array}{l}\text { tttTGAACTTctgtctgaaAGGTCActt } \\
\text { tttTGAATTctgtctgaaAGGTCActt }\end{array}$ & ER9 & $\times 10$ & $\begin{array}{c}74.4 \pm 0.4 \\
\text { Not detected }\end{array}$ \\
\hline rs181870712 & CSMD1 (+5915) & $\begin{array}{l}\text { caaAGGTCActtaAGGTCAttt } \\
\text { caaAAGTCActtaAGGTCAttt }\end{array}$ & DR4 & $\times 10$ & $\begin{array}{l}62.9 \pm 1.1 \\
26.0 \pm 1.5\end{array}$ \\
\hline rs117662912 & CETN3 $(+144,942)$ & $\begin{array}{l}\text { aggAGGTCAggaggAGTTCActg } \\
\text { aggAAGTCAggaggAGTTCActg }\end{array}$ & DR5 & $\times 10$ & $\begin{array}{l}56.9 \pm 0.9 \\
17.9 \pm 0.6\end{array}$ \\
\hline rs113398776 & SLC9A2 $(+30,825)$, MFSD9 $(+86,346)$ & $\begin{array}{l}\text { tgaAGGTCAaagAGTTTAаса } \\
\text { tgaAGGTCAaagAGATTAaca }\end{array}$ & DR3 & $\times 100$ & $\begin{array}{l}95.5 \pm 0.9 \\
9.5 \pm 1.1\end{array}$ \\
\hline rs190307664 & ESM1 (+232,659), SNX18 $(+235,162)$ & 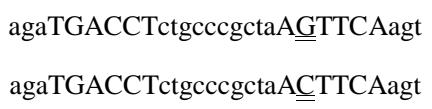 & ER10 & $\times 100$ & $\begin{array}{l}101.8 \pm 1.5 \\
36.5 \pm 0.9\end{array}$ \\
\hline rs115070434 & MPDZ $(-24,841)$ & $\begin{array}{l}\text { taaAGGTTAaatgAGGTC } \underline{\underline{A}} \text { cta } \\
\text { taaAGGTTAaatgAGGTCECcta }\end{array}$ & DR4 & $\times 100$ & $\begin{array}{l}102.8 \pm 1.1 \\
66.3 \pm 5.7\end{array}$ \\
\hline rs148735323 & NOX5 (-76,449), SPESP1 (+7746) & 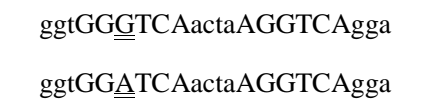 & DR4 & $\times 100$ & $\begin{array}{l}97.6 \pm 0.4 \\
71.1 \pm 0.8\end{array}$ \\
\hline rs145145243 & EYA4 (-231,989), RPS12 (+194,798) & $\begin{array}{l}\text { agtGGTTCAatcacAGTTC } \underline{\underline{A}} \mathrm{ctg} \\
\text { agtGGTTCAatcacAGTTCTctg }\end{array}$ & DR5 & $\times 100$ & $\begin{array}{l}94.4 \pm 0.9 \\
60.7 \pm 1.5\end{array}$ \\
\hline rs369662801 & RTN4RL1 (+9904), RPA1 $(+185,001)$ & $\begin{array}{l}\operatorname{tggAGCTCAg} \underline{\underline{A} G T T C A a a g} \\
\operatorname{tggAGCTCAg} \underline{\underline{C G T T C A a a g}}\end{array}$ & DR1 & $\times 100$ & $\begin{array}{l}82.1 \pm 0.5 \\
22.1 \pm 5.5\end{array}$ \\
\hline rs79536015 & RPIA $(+385,204)$ & 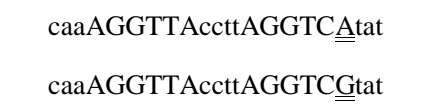 & DR4 & $\times 100$ & $\begin{array}{l}96.5 \pm 0.2 \\
67.5 \pm 0.9\end{array}$ \\
\hline $\begin{array}{l}\text { rs4497728 } \\
\text { rs4303542 } \\
\text { rs4307980 }\end{array}$ & MTRNR2L1 $(+228,816)$ & 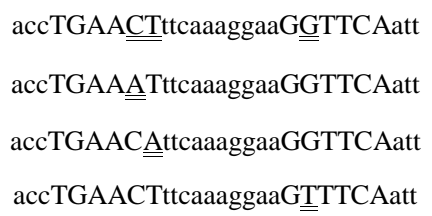 & ER10 & $\times 100$ & $\begin{array}{l}94.5 \pm 2.1 \\
20.2 \pm 0.5 \\
23.5 \pm 0.6 \\
68.6 \pm 0.9\end{array}$ \\
\hline rs138716773 & PRL $(-745,604)$ & 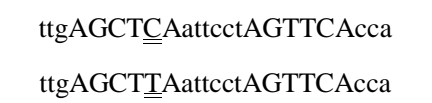 & DR6 & $\times 100$ & $\begin{array}{l}62.6 \pm 2.4 \\
12.0 \pm 3.9\end{array}$ \\
\hline rs11914034 & ACR $(+12,179)$, RABL2B $(+33,256)$ & $\begin{array}{l}\text { caaAGGACA } \underline{\underline{A} T G A A C T c t t} \\
\text { caaAGGACGTGAACTctt }\end{array}$ & IR0 & $\times 100$ & $\begin{array}{l}46.9 \pm 0.7 \\
77.6 \pm 0.5\end{array}$ \\
\hline
\end{tabular}

It has been reported that CAR/RXR $\alpha$ can bind promiscuously to multiple DNA binding motifs such as DR1 [35], DR3 [7], DR4 [8] [12] [36]-[38], DR5 [2] [11], ER6 [7], ER7 [39], ER8 [40], ER9 [39], ER10 [39], IR2 [10], IR3 [41], and IR6 [42]. In addition to these motif types, our results indicated that CAR/RXR $\alpha$ could bind to DR2, DR6, DR8-10, ER1, ER3, ER4, ER5, IR0, and IR7 (Figure 3(b) and Table 2). As these motif types 
overlap with the binding sequences for other nuclear receptors, CAR/RXR $\alpha$ would compete for binding to these elements and cross talk with other nuclear receptors [35] [38] [41]. On the other hand, CAR/RXR $\alpha$ may preferably bind to DR4 relative to the other motifs, because DR4 motif was enriched by motif enrichment among 414 clones (Figure 2).

We could not identify the previously reported CAR/RXR $\alpha$-binding sites in this study. There are some explanations for missed CAR/RXRDNA interactions. First, the quality of a library will affect the efficiency of identification of protein-DNA interactions. Second, some CAREs may exist adjacent to sequences recognized by yeast transcription factors and may be discarded during the negative selection by 5FOA [8]. However, we could identified new CAR/RXR $\alpha$ binding sites located in or in the proximity of genes with various functions such as metabolic process, cell cycle, cell proliferation and apoptosis. In particular, Heat shock $70 \mathrm{kDa}$ protein $1 \mathrm{~A}$ (HSPA1A) is known as a stress inducible gene that promotes liver tumor cell proliferation [43]. Importantly, the HSPA1A gene was reported as a CAR-dependent gene in a microarray analysis of CAR-knockout mice [15]. Furthermore, we confirmed the CAR-dependent activation of human HSPA1A mRNA expression in human hepatoma HepG2 cells by real-time PCR assays (data not shown). CAR is thought to be essential for liver tumor promotion via the direct regulation of the Mdm2 gene [44] [45]. In addition to this mechanism, our results suggested that CAR is associated with liver tumor promotion via direct regulation of HSPA1A.

ChIP-on-chip or ChIP seq techniques are powerful methods for identifying transcription factor-DNA interactions. However, these methods can also identify potential indirect transcription factor-DNA interactions. In contrast, our strategy for the identification of $\mathrm{CAR} / \mathrm{RXR} \alpha$ binding sites in the human genome was fundamentally different and was based on the direct interaction of CAR/RXR $\alpha$ with human genomic sequences using yeast genetic selection. We expect that these findings will provide insights into the molecular mechanisms underlying the physiological and pathological actions of CAR/RXR $\alpha$ heterodimers.

\section{Conclusion}

In this paper, we identified $\mathrm{CAR} / \mathrm{RXR} \alpha$-binding sequences in the human genome by a modified yeast one-hybrid assay. The binding sites were located in the proximity of genes with various functions such as metabolic process, cell cycle, cell proliferation and apoptosis. Motif enrichment analysis revealed that the most frequently observed motif was a DR4, although the identified sequences contained not only classical CAREs but also a wide variety of arrangements. Next, we demonstrated that 108 human genomic fragments could directly interact with the CAR/RXR $\alpha$ heterodimer by EMSAs. Furthermore, we identified 17 regulatory polymorphisms on the CAR/RXR $\alpha$-binding sites which may influence individual variation of expression levels of CAR-regulated genes. We expect that these findings will provide insights into the molecular mechanisms underlying the physiological and pathological actions of $\mathrm{CAR} / \mathrm{RXR} \alpha$ heterodimers.

\section{Acknowledgements}

We would like to thank Mr. Takatsugu Kosugi, Mr. Shogo Wakabayashi, and Mr. Natsuhiro Honda for their helpful discussion and excellent technical assistance.

\section{Declaration of Interest}

This work was supported by JSPS KAKENHI Grant Number 30360704. The authors report no conflicts of interest. The authors alone are responsible for the content and writing of this paper.

\section{References}

[1] Chawla, A., Repa, J.J., Evans, R.M. and Mangelsdorf, D.J. (2001) Nuclear Receptors and Lipid Physiology: Opening the X-Files. Science, 294, 1866-1870. http://dx.doi.org/10.1126/science.294.5548.1866

[2] Baes, M., Gulick, T., Choi, H.S., Martinoli, M.G., Simha, D. and Moore, D.D. (1994) A New Orphan Member of the Nuclear Hormone Receptor Superfamily That Interacts with a Subset of Retinoic Acid Response Elements. Molecular and Cellular Biology, 14, 1544-1552.

[3] Lamba, J.K., Lamba, V., Yasuda, K., Lin, Y.S., Assem, M., Thompson, E., Strom, S. and Schuetz, E. (2004) Expression of Constitutive Androstane Receptor Splice Variants in Human Tissues and Their Functional Consequences. Journal of Pharmacology and Experimental Therapeutics, 311, 811-821. http://dx.doi.org/10.1124/jpet.104.069310 
[4] Kobayashi, K., Sueyoshi, T., Inoue, K., Moore, R. and Negishi, M. (2003) Cytoplasmic Accumulation of the Nuclear Receptor CAR by a Tetratricopeptide Repeat Protein in HepG2 Cells. Molecular Pharmacology, 64, 1069-1075. http://dx.doi.org/10.1124/mol.64.5.1069

[5] Yoshinari, K., Kobayashi, K., Moore, R., Kawamoto, T. and Negishi, M. (2003) Identification of the Nuclear Receptor CAR:HSP90 Complex in Mouse Liver and Recruitment of Protein Phosphatase 2A in Response to Phenobarbital, FEBS Letters, 548, 17-20. http://dx.doi.org/10.1016/S0014-5793(03)00720-8

[6] Goodwin, B., Moore, L.B., Stoltz, C.M., McKee, D.D. and Kliewer, S.A. (2001) Regulation of the Human CYP2B6 Gene by the Nuclear Pregnane X Receptor. Molecular Pharmacology, 60, 427-431.

[7] Goodwin, B., Hodgson, E., D’Costa, D.J., Robertson, G.R. and Liddle, C. (2002) Transcriptional Regulation of the Human CYP3A4 Gene by the Constitutive Androstane Receptor. Molecular Pharmacology, 62, 359-365. http://dx.doi.org/10.1124/mol.62.2.359

[8] Gerbal-Chaloin, S., Daujat, M., Pascussi, J.M., Pichard-Garcia, L., Vilarem, M.J. and Maurel, P. (2002) Transcriptional Regulation of CYP2C9 Gene Role of Glucocorticoid Receptor and Constitutive Androstane Receptor. The Journal of Biological Chemistry, 277, 209-217. http://dx.doi.org/10.1074/jbc.M107228200

[9] Sugatani, J., Kojima, H., Ueda, A., Kakizaki, S., Yoshinari, K., Gong, Q.H., Owens, I.S., Negishi, M. and Sueyoshi, T. (2001) The Phenobarbital Response Enhancer Module in the Human Bilirubin UDP-glucuronosyltransferase UGT1A1 Gene and Regulation by the Nuclear Receptor CAR. Hepatology, 33, 1232-1238. http://dx.doi.org/10.1053/jhep.2001.24172

[10] Chen, X., Zhang, J., Baker, S.M. and Chen, G. (2007) Human Constitutive Androstane Receptor Mediated Methotrexate Induction of Human Dehydroepiandrosterone Sulfotransferase (hSULT2A1). Toxicology, 231, 224-233. http://dx.doi.org/10.1016/j.tox.2006.12.019

[11] Benoki, S., Yoshinari, K., Chikada, T., Imai, J. and Yamazoe, Y. (2012) Transactivation of ABCG2 through a Novel cis-Element in the Distal Promoter by Constitutive Androstane Receptor but Not Pregnane X Receptor in Human Hepatocytes. Archives of Biochemistry and Biophysics, 517, 123-130. http://dx.doi.org/10.1016/j.abb.2011.10.014

[12] Sueyoshi, T., Kawamoto, T., Zelko, I., Honkakoski, P. and Negishi, M. (1999) The Repressed Nuclear Receptor CAR Responds to Phenobarbital in Activating the Human CYP2B6 Gene. Journal of Biological Chemistry, 274, 6043-6046. http://dx.doi.org/10.1074/jbc.274.10.6043

[13] Ueda, A., Hamadeh, H.K., Webb, H.K., Yamamoto, Y., Sueyoshi, T., Afshari, C.A., Lehmann, J.M. and Negishi, M. (2002) Diverse Roles of the Nuclear Orphan Receptor CAR in Regulating Hepatic Genes in Response to Phenobarbital. Molecular Pharmacology, 61, 1-6. http://dx.doi.org/10.1124/mol.61.1.1

[14] Maglich, J.M., Parks, D.J., Moore, L.B., Collins, J.L., Goodwin, B., Billin, A.N., Stoltz, C.A., Kliewer, S.A., Lambert, M.H., Willson, T.M. and Moore, J.T. (2003) Identification of a Novel Human Constitutive Androstane Receptor (CAR) Agonist and Its Use in the Identification of CAR Target Genes. Journal of Biological Chemistry, 278, 17277-17283. http://dx.doi.org/10.1074/jbc.M300138200

[15] Tojima, H., Kakizaki, S., Yamazaki, Y., Takizawa, D., Horiguchi, N., Sato, K. and Mori, M. (2012) Ligand Dependent Hepatic Gene Expression Profiles of Nuclear Receptors CAR and PXR. Toxicology Letters, 212, 288-297. http://dx.doi.org/10.1016/j.toxlet.2012.06.001

[16] Tamasi, V., Juvan, P., Beer, M., Rozman, D. and Meyer, U.A. (2009) Transcriptional Activation of PPAR Alpha by Phenobarbital in the Absence of CAR and PXR. Molecular Pharmaceutics, 6, 1573-1581. http://dx.doi.org/10.1021/mp9001552

[17] Cui, J.Y., Gunewardena, S.S., Rockwell, C.E. and Klaassen, C.D. (2010) ChIPing the Cistrome of PXR in Mouse Liver. Nucleic Acids Research, 38, 7943-7963. http://dx.doi.org/10.1093/nar/gkq654

[18] Mahony, S., Mazzoni, E.O., McCuine, S., Young, R.A., Wichterle, H. and Gifford, D.K. (2011) Ligand-Dependent Dynamics of Retinoic Acid Receptor Binding during Early Neurogenesis. Genome Biology, 12, R2. http://dx.doi.org/10.1186/gb-2011-12-1-r2

[19] Delacroix, L., Moutier, E., Altobelli, G., Legras, S., Poch, O., Choukrallah, M.A., Bertin, I., Jost, B. and Davidson, I. (2010) Cell-Specific Interaction of Retinoic Acid Receptors with Target Genes in Mouse Embryonic Fibroblasts and Embryonic Stem Cells. Molecular and Cellular Biology, 30, 231-244. http://dx.doi.org/10.1128/MCB.00756-09

[20] Hua, S., Kittler, R. and White, K.P. (2009) Genomic Antagonism between Retinoic Acid and Estrogen Signaling in Breast Cancer. Cell, 137, 1259-1271. http://dx.doi.org/10.1016/j.cell.2009.04.043

[21] Verzi, M.P., Shin, H., San Roman, A.K., Liu, X.S. and Shivdasani, R.A. (2013) Intestinal Master Transcription Factor CDX2 Controls Chromatin Access for Partner Transcription Factor Binding. Molecular and Cellular Biology, 33, 281292. http://dx.doi.org/10.1128/MCB.01185-12

[22] Reddy, T.E., Pauli, F., Sprouse, R.O., Neff, N.F., Newberry, K.M., Garabedian, M.J. and Myers, R.M. (2009) Genomic Determination of the Glucocorticoid Response Reveals Unexpected Mechanisms of Gene Regulation. Genome Re- 
search, 19, 2163-2171. http://dx.doi.org/10.1101/gr.097022.109

[23] Nielsen, R., Pedersen, T.A., Hagenbeek, D., Moulos, P., Siersbaek, R., Megens, E., Denissov, S., Børgesen, M., Francoijs, K.J., Mandrup, S. and Stunnenberg, H.G. (2008) Genome-Wide Profiling of PPAR $\gamma$ : RXR and RNA Polymerase II Occupancy Reveals Temporal Activation of Distinct Metabolic Pathways and Changes in RXR Dimer Composition during Adipogenesis. Genes \& Development, 22, 2953-2967. http://dx.doi.org/10.1101/gad.501108

[24] Taniguchi-Yanai, K., Koike, Y., Hasegawa, T., Furuta, Y., Serizawa, M., Ohshima, N., Kato, N. and Yanai, K. (2010) Identification and Characterization of Glucocorticoid Receptor-Binding Sites in the Human Genome. Journal of Receptors and Signal Transduction, 30, 88-105. http://dx.doi.org/10.3109/10799891003614816

[25] Kanno, Y., Aoki, S., Mochizuki, M., Mori, E., Nakahama, T. and Inouye, Y. (2005) Expression of Constitutive Androstane Receptor Splice Variants in Rat Liver and Lung and Their Functional Properties. Biological and Pharmaceutical Bulletin, 28, 2058-2062. http://dx.doi.org/10.1248/bpb.28.2058

[26] Auerbach, S.S., Dekeyser, J.G., Stoner, M.A. and Omiecinski, C.J. (2007) CAR2 Displays Unique Ligand Binding and RXR $\alpha$ Heterodimerization Characteristics. Drug Metabolism and Disposition, 35, 428-439. http://dx.doi.org/10.1124/dmd.106.012641

[27] Wang, H., Faucette, S., Sueyoshi, T., Moore, R., Ferguson, S., Negishi, M. and LeCluyse, E.L. (2003) A Novel Distal Enhancer Module Regulated by Pregnane X Receptor/Constitutive Androstane Receptor Is Essential for the Maximal Induction of CYP2B6 Gene Expression. Journal of Biological Chemistry, 278, 14146-14152. http://dx.doi.org/10.1074/jbc.M212482200

[28] Goecks, J., Nekrutenko, A. and Taylor, J., The Galaxy Team (2010) Galaxy: A Comprehensive Approach for Supporting Accessible, Reproducible, and Transparent Computational Research in the Life Sciences. Genome Biology, 11, R86. http://dx.doi.org/10.1186/gb-2010-11-8-r86

[29] Blankenberg, D., Von Kuster, G., Coraor, N., Ananda, G., Lazarus, R., Mangan, M., Nekrutenko, A. and Taylor, J. (2010) Galaxy: A Web-Based Genome Analysis Tool for Experimentalists. Current Protocols in Molecular Biology, 19, 10.1-10.21.

[30] Giardine, B., Riemer, C., Hardison, R.C., Burhans, R., Elnitski, L., Shah, P., Zhang, Y., Blankenberg, D., Albert, I., Taylor, J., Miller, W., Kent, W.J. and Nekrutenko, A. (2005) Galaxy: A Platform for Interactive Large-Scale Genome Analysis. Genome Research, 15, 1451-1455. http://dx.doi.org/10.1101/gr.4086505

[31] McLean, C.Y., Bristor, D., Hiller, M., Clarke, S.L., Schaar, B.T., Lowe, C.B., Wenger, A.M. and Bejerano, G. (2010) GREAT Improves Functional Interpretation of cis-Regulatory Regions. Nature Biotechnology, 28, 495-501. http://dx.doi.org/10.1038/nbt.1630

[32] Hasegawa, K., Cowan, A.B., Nakatsuji, N. and Suemori, H. (2007) Efficient Multicistronic Expression of a Transgene in Human Embryonic Stem Cells. Stem Cells, 25, 1707-1712. http://dx.doi.org/10.1634/stemcells.2006-0813

[33] Kawamoto, T., Sueyoshi, T., Zelko, I., Moore, R., Washburn, K. and Negishi, M. (1999) Phenobarbital-Responsive Nuclear Translocation of the Receptor CAR in Induction of the CYP2B Gene. Molecular and Cellular Biology, 19, 6318-6322.

[34] Machanick, P. and Bailey, T.L. (2011) MEME-ChIP: Motif Analysis of Large DNA Datasets. Bioinformatics, 27, 1696-1697. http://dx.doi.org/10.1093/bioinformatics/btr189

[35] Miao, J., Fang, S., Bae, Y. and Kemper, J.K. (2006) Functional Inhibitory Cross-Talk between Constitutive Androstane Receptor and Hepatic Nuclear Factor-4 in Hepatic Lipid/Glucose Metabolism Is Mediated by Competition for Binding to the DR1 Motif and to the Common Coactivators, GRIP-1 and PGC-1 $\alpha$. Journal of Biological Chemistry, 281, 14537-14546. http://dx.doi.org/10.1074/jbc.M510713200

[36] Burk, O., Arnold, K.A., Geick, A., Tegude, H. and Eichelbaum, M. (2005) A Role for Constitutive Androstane Receptor in the Regulation of Human Intestinal MDR1 Expression. Biological Chemistry, 386, 503-513. http://dx.doi.org/10.1515/BC.2005.060

[37] Yoshinari, K., Ohno, H., Benoki, S. and Yamazoe, Y. (2012) Constitutive Androstane Receptor Transactivates the Hepatic Expression of Mouse Dhcr24 and Human DHCR24 Encoding a Cholesterogenic Enzyme 24-Dehydrocholesterol Reductase. Toxicology Letters, 208, 185-191. http://dx.doi.org/10.1016/j.toxlet.2011.11.003

[38] Chen, Y., Ferguson, S.S., Negishi, M. and Goldstein, J.A. (2003) Identification of Constitutive Androstane Receptor and Glucocorticoid Receptor Binding Sites in the CYP2C19 Promoter. Molecular Pharmacology, 64, 316-324. http://dx.doi.org/10.1124/mol.64.2.316

[39] Frank, C., Gonzalez, M.M., Oinonen, C., Dunlop, T.W. and Carlberg, C. (2003) Characterization of DNA Complexes Formed by the Nuclear Receptor Constitutive Androstane Receptor. Journal of Biological Chemistry, 278, 4329943310. http://dx.doi.org/10.1074/jbc.M305186200

[40] Kast, H.R., Goodwin, B., Tarr, P.T., Jones, S.A., Anisfeld, A.M., Stoltz, C.M., Tontonoz, P., Kliewer, S., Willson, T.M. and Edwards, P.A. (2002) Regulation of Multidrug Resistance-Associated Protein 2 (ABCC2) by the Nuclear Recep- 
tors Pregnane X Receptor, Farnesoid X-Activated Receptor, and Constitutive Androstane Receptor. Journal of Biological Chemistry, 277, 2908-2915. http://dx.doi.org/10.1074/jbc.M109326200

[41] Min, G., Kim, H., Bae, Y., Petz, L. and Kemper, J.K. (2002) Inhibitory Cross-Talk between Estrogen Receptor (ER) and Constitutively Activated Androstane Receptor (CAR) CAR Inhibits ER-Mediated Signaling Pathway by Squelching p160 Coactivators. Journal of Biological Chemistry, 277, 34626-34633. http://dx.doi.org/10.1074/jbc.M205239200

[42] Xie, W., Barwick, J.L., Simon, C.M., Pierce, A.M., Safe, S., Blumberg, B., Guzelian, P.S. and Evans, R.M. (2000) Reciprocal Activation of Xenobiotic Response Genes by Nuclear Receptors SXR/PXR and CAR. Genes \& Development, 14, 3014-3023. http://dx.doi.org/10.1101/gad.846800

[43] Wu, F.H., Yuan, Y., Li, D., Liao, S.J., Yan, B., Wei, J.J., Zhou, Y.H., Zhu, J.H., Zhang, G.M. and Feng, Z.H. (2012) Extracellular HSPA1A Promotes the Growth of Hepatocarcinoma by Augmenting Tumor Cell Proliferation and Apoptosis-Resistance. Cancer Letters, 317, 157-164. http://dx.doi.org/10.1016/j.canlet.2011.11.020

[44] Huang, W., Zhang, J., Washington, M., Liu, J., Parant, J.M., Lozano, G. and Moore, D.D. (2005) Xenobiotic Stress Induces Hepatomegaly and Liver Tumors via the Nuclear Receptor Constitutive Androstane Receptor. Molecular Endocrinology, 19, 1646-1653. http://dx.doi.org/10.1210/me.2004-0520

[45] Yamamoto, Y., Moore, R., Goldsworthy, T.L., Negishi, M. and Maronpot, R.R. (2004) The Orphan Nuclear Receptor Constitutive Active/Androstane Receptor Is Essential for Liver Tumor Promotion by Phenobarbital in Mice. Cancer Research, 64, 7197-7200. http://dx.doi.org/10.1158/0008-5472.CAN-04-1459 